\title{
Restless Legs Syndrome During Pregnancy and Preterm Birth in Women Referred to Health Centers of Ardabil
}

\author{
Zahra Meharaban," Somayeh Yahya, ${ }^{2}$ and Khosro Sadegniiat ${ }^{3}$ \\ ${ }^{1}$ Department of Midwifery, Ardabil Branch, Islamic Azad University, Ardabil, IR Iran \\ ${ }_{3}^{2}$ Department of Midwifery, Rasht Branch, Islamic Azad University, Rasht, IR Iran \\ ${ }^{3}$ Occupational Sleep Research Center, Baharloo Hospital, Tehran University of Medical Sciences, Tehran, IR Iran \\ ${ }^{*}$ Corresponding Author: Zahra Meharaban, Department of Midwifery, Ardabil Branch, Islamic Azad University, Ardabil, IR Iran. Tel: +98-4517728024, Fax: +98-4517715514, \\ E-mail:zahraob81@yahoo.com
}

Received 2014 October 16; Revised 2015 August 15; Accepted 2015 September 8.

\begin{abstract}
Background:The physiological changes of pregnancy may predispose females to develop restless legs syndrome (RLS). Studies evaluating outcomes of RLS symptoms in pregnancy are scarce.

Objectives: We examined the risk of preterm birth in pregnant women with and without restless legs syndrome (RLS).

Materials and Methods: A cohort study included 231 pregnant women attending Ardabil health care centers for prenatal care and delivery in the period of 2010, without any risk factors for preterm delivery and low birth weight. The instruments used were questionnaires about RLS, the Epworth sleepiness scale (ESS), demographic data, and hemoglobin values. Data were analyzed via SPSS software using descriptive statistics, the t-test, $\chi 2$, Fisher's exact test, Pearson's correlation, and the Mann-Whitney U test.

Results: RLS complicated 43.7 percent of pregnancies. Sleepiness (ESS score $>8$ ) was reported in $36.4 \%$ of the subjects with preterm birth and $35.9 \%$ of the term group. No significant correlation was found between the ESS score and the term and preterm groups $(\mathrm{P}=0.843)$. The prevalence of preterm birth in the subjects with and without RLS was $69.7 \%$ and $30.3 \%$, respectively: As a result, it significantly increased in the RLS group $(\mathrm{P}=0.001)$.

Conclusions: Pregnancies complicated by RLS are at increased risk for preterm birth. The improved sleep health of pregnant women could decrease pregnancy complications.
\end{abstract}

Keywords: Restless Legs Syndrome, Iran, Pregnancy, Epworth Sleepiness Scale (ESS) Score, Preterm Birth

\section{Background}

Sleep disturbance is more prevalent during the third trimester of pregnancy and results in excessive daytime sleepiness, fatigue, or the inability to concentrate; a sleep disorder may be present (1). Pregnancy alters sleep patterns and one's quality of sleep due to hormonal, anatomical, and mechanical changes (2). Two underdiagnosed sleep disorders that commonly occur in the third trimester are leg cramps (LCs) and restless legs syndrome (RLS). The risk of RLS in pregnant women is two to three times higher than it is in other women $(3,4)$. Between 11 and 27 percent of pregnant women experience RLS during pregnancy without any particular causes (5). Most symptoms are more prevalent in the third trimester (6). The main cause of RLS with pregnancy is unclear.

Manconi et al. (7) showed a statistically significant lower incidence of total sleep time in women who experienced RLS in the third trimester when compared with a healthy group of gravid women $(\mathrm{P}<0.051)$. It appears that a sleep disturbance because of LCs or RLS during pregnancy could adversely affect functionality during daytime hours and perhaps the length of sleep time and quality of life $(1,6,8)$. Also, the majority of RLS diagnosed during pregnancy will be secondary (i.e. directly related to the pregnancy itself or to iron depletion) $(3,7,9)$. According to reports, anemia, particularly iron-deficiency anemia, is a more prevalent disorder in women in Iran (10-12). This has led to a prevalence of RLS, which could be complicating pregnancies in women (13). The hypothesis that "pregnancies are complicated by sleep disruption" is biologically logical. First, pregnancy has been associated with alterations in sleep (14). Pregnant women need adequate sleep for their health and fetal development, and RLS may have a negative impact on the quality of their sleep $(3,4,12)$.

Second, diseases, such as hypertension, diabetes, and depression, that have been related to sleep problems in the non-pregnant population have been correlated with pregnancy (e.g. gestational diabetes, gestational hypertension, and preterm birth) (15-17). It has been hypothesized that poor sleep in pregnancy contributes to increased risk of complications, such as intrauterine growth retardation and preterm labor (18-20).

\section{Objectives}

Due to iron deficiency, anemia is more prevalent among

Copyright (C) 2015, Iranian Red Crescent Medical Journal. This is an open-access article distributed under the terms of the Creative Commons Attribution-NonCommercial 4.0 International License (http://creativecommons.org/licenses/by-nc/4.0/) which permits copy and redistribute the material just in noncommercial usages, provided the original work is properly cited. 
Iranian women. Also, the literature regarding the outcome of pregnancies complicated by RLS is very rare (12, 14). Thus, we performed this cohort study to further explore the associations between the presence of RLS and preterm birth.

\section{Materials and Methods}

All qualified pregnant women were invited to participate in an ongoing prospective study from March to December 2011. We applied a multistage sampling method to choose study subjects. In the first stage of sampling, we divided the city of Ardabil geographically into four areas (east, west, north, and south). In the second stage, we selected four health care centers (Bakeri, Shahid Hatami, Azadegan, and Bahonar) from 14 centers by chance. Finally, we randomly selected 241 mothers from a list of pregnant women.

Based on an evaluation of the studies, the preterm birth rate was $15 \%$, and an estimated $30 \%$ was attributed to factors and a two-tailed $\alpha$ of 0.05 . A total sample of 200 was needed with complete data to have sufficient statistical power. A total of 241 participants were selected only from singleton pregnancies between 28 to 32 weeks of gestational age. Participants who had factors related to preterm labor and sleep disorder were excluded; these factors included: 1) having previous preterm birth or spontaneous abortion; 2 ) less than 18 years old or greater than 45 years of age; 3 ) suffering from chronic illnesses or obstetrical complications; 4) having currently diagnosed obstetrical complications; and 5) having any psychological or sleep disorders before or during pregnancy. The Ardabil branch of the Islamic Azad University committee approved the final study design. All participants were informed about the study, and informed consent was obtained from them.

Demographic data were collected from participants' health files. RLS and sleepiness were determined by using the researcher-designed International RLS study group rating scale (IRLS) (21) and the excessive sleepiness scale (ESS), which were validated in the Iranian population (8).

Regarding attrition rates, 241 women completed questionnaires, of which 10 dropped out of the study and were excluded from analyses.

Clinical criteria were used for the diagnosis of RLS reviewed in the 2003 (Walters et al. 2003) international RLS study group rating scale (IRLS) (21, 22). Although the original IRLS (version 1.0) was already validated (17), the criteria for determining RLS included a persistent movement of legs attended or caused by a painful and unpleasant feeling in the legs that becomes worse during periods of rest or immobility. The questionnaire contained 10 questions with scores ranging from 0 to 4 . Totaling these scores, the patients' RLS were grouped as mild (scores from 0 to 10 ), moderate (11 to 20 ), and severe (21 to 30 ). Finally, the women were classified as two groups according to the presence or lack thereof of RLS.

We also evaluated daytime sleepiness because of RLS by using the ESS. The ESS measures the general level of daytime sleepiness by noting individuals' rate of dozing during eight different daytime situations (10). The scale ranges from 0 to 24 , and excessive daytime sleepiness was defined as a total score of 10 or more.

Internal consistency reliability ( $\alpha$ Cronbach) for the questionnaire on ESS was 0.771, and for the RLS questionnaire, it was 0.869 , which is considered to be reliable $(6,12,21)$. Laboratory values were measured using a standard measurement assay. Anemia was determined as a serum hemoglobin level $\leq 11 \mathrm{~g} / \mathrm{dl}$ that was measured twice, once at the first trimester and a second time at the $28^{\text {th }}$ week of pregnancy.

Finally, 231 pregnant women were followed until 37 weeks of pregnancy for the occurrence of preterm delivery. Gestational age was defined from the first day of the last menstrual period (LMP). When the LMP was unknown, the ultrasound assessment of gestational age was used.

After delivery, data were obtained from the family health files of subjects when they were referred to health centers. If women were not referred to health centers, the researchers would follow up with the women using the addresses and phone numbers in the family health files.

We analyzed the data by using SPSS (statistical package for social science) version 17 . Mean \pm standard deviations (SD) were declared for continuous variables, and categorical variables were framed as numbers and percentages. An independent Mann-Whitney U test, the $\chi^{2}$, and Fisher's exact test or the t-test were applied to compare data between pregnant women with and without RLS. The severity and frequency of RLS symptoms was analyzed by Pearson's correlation.

\section{Results}

\subsection{Subject Characteristics}

A total of 241 pregnant women were asked to complete the sleep disorder questionnaire to assess RLS and daytime sleepiness. A total of 10 women were disqualified from analysis because they had either obstetrical complications (preterm birth, preeclampsia, vaginal bleeding, etc.) or medical complications.

The study of 231 pregnant women showed that 20 (8.7\%) of them had no RLS symptoms, 110 (47.6\%) had mild RLS, 88 (38.1\%) had moderate RLS, and 13 (5.6\%) had severe RLS. With regard to the low number of cases without RLS symptoms, we merged them with the mild impairment group and defined them as a group without the RLS; groups with moderate and severe RLS became an RLS group. Therefore, 130 subjects (56.3\%) had no RLS, and 101 women (43.7\%) had RLS.

The mean duration of pregnancy in the group with RLS and without RLS was (mean \pm SD) $38.6 \pm 1.7$ weeks and 38.7 \pm 1.4 weeks, respectively. The pregnant women with RLS were younger. Also, the housewives had higher body mass indexes (BMIs), and almost all of their education levels were in the range of upper high school. However, no significant relationship existed between RLS and variables 
Table 1. Demographic Characteristics of the Pregnant Women in the Study Population ${ }^{\mathrm{a}}$

\begin{tabular}{|c|c|c|}
\hline Characteristic & Women Without RLS & Women With RLS \\
\hline \multicolumn{3}{|l|}{ Age, $y$} \\
\hline $18-24$ & $56(43.1)$ & $40(39.6)$ \\
\hline $25-29$ & $40(30.8)$ & $28(27.7)$ \\
\hline $30-34$ & $29(22.3)$ & $28(27.7)$ \\
\hline $35-45$ & $5(3.8)$ & $5(5)$ \\
\hline \multicolumn{3}{|l|}{ BMI, $\mathrm{kg} / \mathrm{m}^{2}$} \\
\hline $19.8>$ & $12(9.3)$ & $9(9.1)$ \\
\hline $19-9.25$ & $55(42.6)$ & $40(40.4)$ \\
\hline $25.1-28$ & $26(20.2)$ & $23(23.2)$ \\
\hline $28.1<$ & $36(27.9)$ & $27(27.3)$ \\
\hline \multicolumn{3}{|l|}{ Education } \\
\hline Initial & $27(20.8)$ & $21(20.8)$ \\
\hline Guidance school & $21(16.2)$ & $17(16.8)$ \\
\hline High school & $59(45.4)$ & $45(44.6)$ \\
\hline University & $23(17.7)$ & $18(17.8)$ \\
\hline \multicolumn{3}{|l|}{ Partner's education } \\
\hline Initial & $28(21.7)$ & $23(22.8)$ \\
\hline Guidance school & $29(22.5)$ & $18(17.8)$ \\
\hline High school & $413(31.8)$ & $48(47.5)$ \\
\hline University & $31(24)$ & $12(11.9)$ \\
\hline \multicolumn{3}{|l|}{ Job } \\
\hline Housekeeper & $124(95.4)$ & $97(96)$ \\
\hline Employe & $6(14.6)$ & $4(4)$ \\
\hline \multicolumn{3}{|l|}{ Partner's job } \\
\hline Employee & $26(20.2)$ & $18(17.8)$ \\
\hline Padrone & $1(0.8)$ & $0(0)$ \\
\hline Worker & $26(20.2)$ & $13(12.9)$ \\
\hline Self-employment & $75(58.1)$ & $68(67.3)$ \\
\hline No work & $1(0.8)$ & $2(2)$ \\
\hline \multicolumn{3}{|l|}{ Marital age, $y$} \\
\hline $5>$ & $70(54.7)$ & $50(49.5)$ \\
\hline $6-9$ & $28(21.9)$ & $27(26.7)$ \\
\hline $10-13$ & $18(14.1)$ & $9(8.9)$ \\
\hline $14<$ & $12(9.4)$ & $15(14.9)$ \\
\hline \multicolumn{3}{|l|}{ Pariety } \\
\hline 1 & $75(58.1)$ & $55(54.5)$ \\
\hline 2 & $34(26.4)$ & $27(26.7)$ \\
\hline 3 & $16(12.4)$ & $12(11.9)$ \\
\hline 4 & $2(1.6)$ & $3(3.0)$ \\
\hline $5<$ & $2(1.6)$ & $4(4)$ \\
\hline
\end{tabular}

Gestetional age at the first

assessment

\begin{tabular}{|lcc|}
\hline 28 & $48(36.9)$ & $39(39)$ \\
\hline 29 & $13(910)$ & $12(12)$ \\
30 & $14(10.8)$ & $8(8)$ \\
31 & $19(14.6)$ & $8(8)$ \\
\hline 32 & $36(27.7)$ & $33(33.0)$ \\
\hline Present weight & & \\
$45-50$ & $4(3.1)$ & $1(1.0)$ \\
\hline $51-60$ & $16(12.4)$ & $9(9.0)$ \\
\hline $61-70$ & $48(37.2)$ & $35(35)$ \\
\hline $71-80$ & $30(23.3)$ & $28(28.0)$ \\
\hline $81-90$ & $24(18.6)$ & $15(15)$ \\
\hline $90<$ & $7(5.4)$ & $12(12)$ \\
\hline Abortion number & & $86(85.1)$ \\
\hline 0 & $116(89.2)$ & $13(12.9)$ \\
\hline 1 & $13(10)$ & $2(2)$ \\
\hline 2 & $1(0.8)$ & \\
\hline${ }^{2}$ Values are presented as No. $(\%)$ & & \\
\hline
\end{tabular}

such as age, education, partner's education, occupation, spouse employment, marriage, gestational age, weight of women at the beginning of the study, caffeine consumption before bed, and delivery type. Demographic characteristics of the samples are represented in Table 1.

\subsection{Hemoglobin and RLS}

The mean hemoglobin at the first antenatal visit was $12.40 \pm 0.86 \mathrm{~g} / \mathrm{dl}$ in the group without RLS and $12.33 \pm 0.84$ $\mathrm{g} / \mathrm{dl}$ in the group with RLS. The mean hemoglobin at 28 32 weeks was $11.86 \pm 1.02 \mathrm{~g} / \mathrm{dl}$ in the group without RLS and $11.98 \pm 0.924 \mathrm{~g} / \mathrm{dl}$ in the RLS group. A total of 155 (64\%) of the subjects' hemoglobin was reduced during pregnancy. Hemoglobin differences were not significant between the with-RLS and without-RLS groups (Table 2).

\subsection{Birth Outcome}

A total of 56 of the 97 pregnant women with RLS delivered by cesarean section. However, women with RLS were more likely to have a normal vaginal delivery instead of a cesarean delivery, but no significant relation was found (48.2\% vs. $40.6 \% ; \mathrm{P}=0.276$ ). The birth weights of the neonates of pregnant women diagnosed with RLS were lower (Table 3 ).

\subsection{Daytime Sleepiness, RLS, and Preterm Labor}

The severity level of RLS indexed among women with and without preterm labor is displayed in Table 4 . A total of 23 (69.7\%) subjects in the preterm group had moderate RLS, while 101(51\%) subjects in the term group had mild RLS.

Table 2. Hemoglobin Mean Between Pregnant Women Diagnosed With and Without RLS ${ }^{\mathrm{a}}$

\begin{tabular}{lccc}
\hline Birth Outcome & $\begin{array}{c}\text { Women } \\
\text { Without RLS }\end{array}$ & $\begin{array}{c}\text { Women } \\
\text { With RLS }\end{array}$ & PValue \\
\hline $\begin{array}{l}\text { Hemoglobin }(28 \\
\text { wk) g/dl }\end{array}$ & $11.86 \pm 1.02$ & $11.98 \pm 0.924$ & 0.354 \\
$\begin{array}{l}\text { First antenatal } \\
\text { hemoglobin }\end{array}$ & $12.40 \pm 0.86$ & $12.33 \pm 0.84$ & 0.422 \\
\hline${ }^{\text {Values are presented as mean } \pm \text { SD. }}$ & & \\
\hline
\end{tabular}

Table 3. Birth Outcome of Pregnant Women Diagnosed With and Without RLS ${ }^{\mathrm{a}}$

\begin{tabular}{lccc}
\hline Birth Outcome & $\begin{array}{c}\text { Women } \\
\text { Without RLS }\end{array}$ & $\begin{array}{c}\text { Women } \\
\text { With RLS }\end{array}$ & P Value \\
\hline $\begin{array}{l}\text { Birth weight, } \\
\text { kg }\end{array}$ & & & 0.971 \\
$2500>$ & $2(1.6)$ & $4(4.2)$ & \\
\hline $2600-3000$ & $36(29)$ & $23(24)$ & \\
\hline $3001-4000$ & $82(66.1)$ & $65(67.7)$ & \\
\hline $4001<$ & $4(3.2)$ & $4(4.2)$ & \\
\hline Delivery type & & & 0.276 \\
\hline C/S & $82(65.1)$ & $56(57.7)$ & \\
\hline NVD & $44(34.9)$ & $41(42.3)$ & \\
\hline
\end{tabular}

${ }^{\mathrm{a}}$ Values are presented as No. (\%). 
Pregnant women with preterm labor slept less than did women with term birth on average (Table 5). Sleepiness (ESS score $>8$ ) was reported in $36.4 \%$ of subjects with preterm birth and $35.9 \%$ of the term group (Table 5). No significant correlation was found between the ESS score and the term and preterm groups $(\mathrm{P}=0.842)$. The score of daytime sleepiness in women with RLS symptoms was significantly increased $(\mathrm{P}=0.001)$. The prevalence of preterm birth in the subjects with and without RLS was 69.7\% and 30.3\%: As a result, it significantly increased in the RLS group $(\mathrm{P}=0.001)$ (Table 5$)$.

\begin{tabular}{lcc}
\hline \multicolumn{2}{l}{ Table 4. RLS Study Group Rating Scale for All Samples ${ }^{\mathrm{a}}$} \\
\hline \multicolumn{1}{l}{ Term } & Preterm \\
\hline RLS severity & $19(9.6)$ & $1(3)$ \\
\hline No & $101(51)$ & $9(27.3)$ \\
\hline Mild & $65(32.8)$ & $23(69.7)$ \\
Moderate & $13(6.6)$ & $0(0)$ \\
\hline Severe & $8.61 \pm 5.38$ & $10.55 \pm 4.25$ \\
\hline Score &
\end{tabular}

Table 5. Sleep Variables Between Women with Term and Preterm Groups $^{\mathrm{a}}$

\begin{tabular}{lccc}
\hline Sleep Variable & Term Group & Preterm Group & P Value \\
\hline RLS & & & $0.001^{\mathrm{b}}$ \\
\multicolumn{1}{|l}{ Without RLS } & $120(60.6)$ & $10(30.3)$ & \\
\hline With RLS & $78(39.4)$ & $23(69.7)$ & \\
$\begin{array}{l}\text { Total sleep } \\
\text { time (>8 h) }\end{array}$ & $1.8 \pm 8.87$ & $2.17 \pm 8.44$ & $0.021^{\mathrm{b}}$ \\
ESS & $3.42 \pm 6.27$ & $3.46 \pm 6.15$ & 0.842 \\
\hline
\end{tabular}

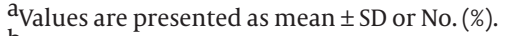

$\mathrm{b}_{\mathrm{P}}<0.05$ were considered statistically significant.

\section{Discussion}

This was one of the first studies that evaluated the relationship between RLS and preterm labor. Studies about obstetrics RLS are few. The prevalence of RLS during pregnancy was 30\% in Pakistan and approximately $26 \%$ in Italy and Turkey $(7,9,22)$. We found RLS prevalence to be about $43.7 \%$ of the pregnant women based on the RLS criteria. The high occurrence of RLS in pregnancy in this article can be due to the high prevalence of anemia in developing countries, such as Iran. Another reason may be genetic influences. RLS was more prevalent in our study maybe due to the fact that anemia was a contributing factor ( 9 , $23,24)$, as has been demonstrated by Italian and Turkish studies $(7,9,25)$.

Hemoglobin concentration was lower in RLS patients (by $11.98 \pm 0.924 \mathrm{~g} / \mathrm{dl}$ ) and in the healthy group (by 11.86 $\pm 1.02 \mathrm{~g} / \mathrm{dl}$ ) in our study than it was in Italian and Turkish studies. Even though anemia was known as an independent predictor of obstetric RLS, the prophylactic effect of supplemental iron was used routinely in pregnancy, which is paradoxical (22).

A total of $59.3 \%$ of the subjects in the preterm group had a total sleep duration time of fewer than eight hours in 24 hours, which was a significant difference between the two groups $(\mathrm{P}=0.021)$. Also, subjects who slept fewer than eight hours had 2.26 times the preterm births $(R R=2.26)$. In one study that examined the relationship between sleep quality and preterm labor, the average night's sleep between the two groups of term and preterm birth was about $7.42 \pm 1.30$ hours, which had no significant difference between the two groups, and the sleep amount's effect on preterm labor was not affected (16). In this study, duration of sleep time was examined with one question that differed according to the subjective perception of sleep duration and individual differences in sleep length. In addition, a more detailed study about the effect of sleep duration on preterm labor should be done with objective methods such as polysomnography and actigraphy (25). In our study, a significant relationship was not found between ESS and preterm birth. The mean ESS score was $6.27 \pm 3.42$ in the term group and 6.15 \pm 3.46 in the preterm group. Previous studies announced that daily dysfunction occurs in 46.2 - $54 \%$ of females during pregnancy (14-16). In these studies, the Pittsburgh questionnaire was used. Naps can diminish the amount of daily dysfunction, but the results of the questionnaires could not definitely determine the value of naps.

RLS is correlated with a lower quality of life (26). We can prove that during pregnancy, RLS had a significant effect on sleep, which can lead to several nocturnal and daily consequences. Although pregnant women with RLS travailed from a higher prevalence of insomnia ranging from $27 \%$ (7) to $64 \%$ (8), nocturia, gastro esophageal reflux, back pain, forced body position in bed, fetal movements, and anxiety for the delivery were frequent causes of insomnia $(7,24)$. The pregnant women also reported more leg cramps (9), a reduction in total sleep time (5), a longer sleep latency $(7,8)$, more difficulty in the onset and maintaining of sleep (7), early morning awakenings (7), more excessive daytime drowsiness (7-9), and snoring (4). In addition, RLS PLM decreased after delivery in subjects with RLS (7-9). In this study, the incidence of preterm birth was observed to be 69.7 percent in the group with RLS. There was a significant difference between groups with and without RLS with preterm delivery $(\mathrm{P}=0.001)$. However, in the relative risk test, it was found that preterm birth was 3.5 times higher in the RLS group (OR 3.5; $95 \%$ CI, $1.5-7.8$ ). In the study Strange et al. (16), 62.5 percent of the sample with poor sleep quality had preterm delivery, but this was not significant.

The result shows that pregnancy is a major non-genetic factor that increases the risk of developing RLS. The hypoth- 
eses about the pathophysiology of RLS during pregnancy remain unclear and include iron or folate deficiency; an increase in estrogen, progesterone, and prolactin levels; psychomotor disruptions; and radiculopathy or peripheral neuropathy (25). Our assumption about these results is that the psychological and physical factor influencing the endocrine and immune systems may play an important role in the relationship between poor sleep quality and preterm birth. The total cesarean section rate was roughly 63.5 percent; there was no significant difference in the type of delivery between the groups. RLS did not raise the incidence of cesarean delivery significantly. However, determining a correlation between the type of delivery and sleep disorders was not one of the goals, to be investigated exactly and with more details, of this research.

The positive aspect of this study is its prospective design and classified questionnaires for the recognition of sleep quality during pregnancy. In addition, healthy samples were chosen. According to the selection procedure, we reduced or eliminated certain potential confounding factors and medical conditions that cause sleep disturbances such as twin pregnancy.

The principal limitation of this study is that it evaluated only subjective sleep symptoms. As such, our results support an estimation of RLS during pregnancy that ideally would be confirmed by further studies using objective measures of sleep time and quality and problems.

\subsection{Conclusion}

RLS is one of the distinct sleep disorders that can negatively influence a pregnant woman's ability to get at least eight hours of sleep per night. RLS could lead to an increased incidence of preterm delivery. A thorough health history can rule out a serious disorder and rule in RLS. Listening to the health concerns of the woman is therapeutic in and of itself and should not be underestimated. Given the impact of sleep on preterm delivery and pregnancy complications, practitioners should address sleep hygiene with women and advocate for a minimum of eight hours sleep per night.

\section{Acknowledgments}

We owe much gratitude to all of the nursing personnel of the mother health care units of the medical department of Ardabil University (Shahid Akhari, Shahid Bakeri, Azadegan, and Bahonar) and the expectant women who participated in this study.

\section{Footnotes}

Authors Contribution:Study concept and design: Zahra Mehraban and Khosro Sadeghniiat; analysis and interpretation of data: Zahra Mehraban, Somayeh Yahya; drafting of the manuscript: Zahra Mehraban; critical revision of the manuscript for important intellectual content:Zahra Mehraban and Khosro Sadeghniiat; statistical analysis: Zahra Mehraban, Somayeh Yahya.
Funding/Support:The article was funded by Islamic Azad University, Ardabil Branch, Ardabil, Iran.

\section{References}

1. Hensley JG. Leg cramps and restless legs syndrome during pregnancy. J Midwifery Womens Health. 2009;54(3):211-8. doi: 10.1016/j. jmwh.2009.01.003. [PubMed:19410213]

2. Neau JP, Marion P, Mathis S, Julian A, Godeneche G, Larrieu D, et al. Restless legs syndrome and pregnancy: follow-up of pregnant women before and after delivery. Eur Neurol. 2010;64(6):361-6. doi:10.1159/000322124. [PubMed: 21088424]

3. Miri S, Rohani M, Vahdat M, Kashanian M, Sariri E, Zamani B, et al. Presenting features of idiopathic versus secondary restless legs syndrome in pregnancy. Iran J Neurol. 2014;13(4):241-4. [PubMed: 25632338]

4. Sarberg M, Josefsson A, Wirehn AB, Svanborg E. Restless legs syndrome during and after pregnancy and its relation to snoring. Acta Obstet Gynecol Scand. 2012;91(7):850-5. doi: 10.1111/j.16000412.2012.01404.x. [PubMed: 22458961]

5. Bartell S, Zallek S. Intravenous magnesium sulfate may relieve restless legs syndrome in pregnancy. J Clin Sleep Med. 2006;2(2):187-8. [PubMed:17557494]

6. Djokanovic N, Garcia-Bournissen F, Koren G. Medications for restless legs syndrome in pregnancy. J Obstet Gynaecol Can. 2008;30(6):505-7. [PubMed: 18611302]

7. Manconi M, Govoni V, De Vito A, Economou NT, Cesnik E, Casetta I, et al. Restless legs syndrome and pregnancy. Neurology. 2004;63(6):1065-9. [PubMed:15452299]

8. Suzuki K, Ohida T, Sone T, Takemura S, Yokoyama E, Miyake T, et al The prevalence of restless legs syndrome among pregnant women in Japan and the relationship between restless legs syndrome and sleep problems. Sleep. 2003;26(6):673-7. [PubMed:14572119]

9. Tunc T, Karadag YS, Dogulu F, Inan LE. Predisposing factors of restless legs syndrome in pregnancy. Mov Disord. 2007;22(5):62731. doi: $10.1002 / \mathrm{mds} .21291$. [PubMed: 17285614$]$

10. Safavi M, Sheikholeslam R, Abdollahi Z, Naghavi M, SadeghianSharif S, Sadeghzadeh E, et al. Prevalence of iron deficiency anemia among Iranian pregnant women, Spring 2001 [In Persian]. Iran J Epidemiology. 2006;2(3):1-10.

11. Esmat B, Mohammad R, Behnam S, Shahrzad M, Soodabeh T, Minoo A, et al. Prevalence of Iron Deficiency Anemia among Iranian Pregnant Women; a Systematic Review and Meta-analysis. J Reprod Infertil. 2010;11(1):17-24. [PubMed:23926476]

12. Ghanei Gheshlagh R, Lanjavani T, Lazari N, Moslemi B. Comparison of the quality of life in pregnant women with and without restless legs syndrome [In Persian]. J Clin Nurs Midwif. 2014;3(1):54-61.

13. Facco FL, Kramer J, Ho KH, Zee PC, Grobman WA. Sleep disturbances in pregnancy. Obstet Gynecol. 2010;115(1):77-83. doi: 10.1097/AOG.0b013e3181c4f8ec. [PubMed: 20027038]

14. Chang JJ, Pien GW, Duntley SP, Macones GA. Sleep deprivation during pregnancy and maternal and fetal outcomes: is there a relationship? Sleep Med Rev. 2010;14(2):107-14. doi: 10.1016/j. smrv.2009.05.001. [PubMed:19625199]

15. Okun ML, Roberts JM, Marsland AL, Hall M. How disturbed sleep may be a risk factor for adverse pregnancy outcomes. Obstet Gynecol Surv. 2009;64(4):273-80. doi: 10.1097/OGX.0b013e318195160e. [PubMed:19296861]

16. Strange LB, Parker KP, Moore ML, Strickland OL, Bliwise DL. Disturbed sleep and preterm birth: a potential relationship? Clin Exp Obstet Gynecol. 2009;36(3):166-8. [PubMed:19860360]

17. Walters AS, LeBrocq C, Dhar A, Hening W, Rosen R, Allen RP, et al. Validation of the International Restless Legs Syndrome Study Group rating scale for restless legs syndrome. Sleep Med. 2003;4(2):121-32. [PubMed:14592342]

18. Okun ML, Luther JF, Wisniewski SR, Sit D, Prairie BA, Wisner KL Disturbed sleep, a novel risk factor for preterm birth? J Womens Health (Larchmt). 2012;21(1):54-60. doi: 10.1089/jwh.2010.2670. [PubMed: 21967121]

19. Sharma SK, Nehra A, Sinha S, Soneja M, Sunesh K, Sreenivas V, et al. Sleep disorders in pregnancy and their association with preg- 
nancy outcomes: a prospective observational study. Sleep Breath. 2015. doi: 10.1007/s11325-015-1188-9. [PubMed: 25957617]

20. Minar M, Habanova H, Rusnak I, Planck K, Valkovic P. Prevalence and impact of restless legs syndrome in pregnancy. Neuro Endocrinol Lett. 2013;34(5):366-71. [PubMed: 23922045]

21. Habibzade H, Khalkhali HR, Ghaneii R. Study of the relationship between restless legs syndrome and sleep disturbance among patients in Critical Care Units. Iran J Crit Care Nurs. 2011;4(3):153-8.

22. Sikandar R, Khealani BA, Wasay M. Predictors of restless legs syndrome in pregnancy: a hospital based cross sectional survey from Pakistan. Sleep Med. 2009;10(6):676-8. doi: 10.1016/j. sleep.2008.06.011. [PubMed:19110469]
23. Neau JP, Texier B, Ingrand P. Sleep and vigilance disorders in pregnancy. Eur Neurol. 2009;62(1):23-9. doi: 10.1159/000215877. [PubMed: 19407452]

24. Gamaldo CE, Earley CJ. Restless legs syndrome: a clinical update. Chest. 2006;130(5):1596-604. doi: 10.1378/chest.130.5.1596. [PubMed: 17099042]

25. Lone FW, Qureshi RN, Emanuel F. Maternal anaemia and its impact on perinatal outcome. Trop Med Int Health. 2004;9(4):48690. doi: 10.1111/j.1365-3156.2004.01222.x. [PubMed:15078267]

26. Neau JP, Porcheron A, Mathis S, Julian A, Meurice JC, Paquereau J, et al. Restless legs syndrome and pregnancy: a questionnaire study in the Poitiers District, France. Eur Neurol. 2010;64(5):26874. doi:10.1159/000321413. [PubMed: 20980760] 